Article

\title{
The Durability of One-Part Alkali-Activated Slag-Based Mortars in Different Environments
}

\author{
Luigi Coppola ${ }^{1,2,3}\left(\mathbb{D}\right.$, Denny Coffetti ${ }^{1,2,3, *}$, Elena Crotti $1,2,3 \oplus$, Gabriele Gazzaniga ${ }^{1,2,3}$ and \\ Tommaso Pastore $1,2,3$ (D) \\ 1 Department of Engineering and Applied Sciences, University of Bergamo, Viale Marconi 5, \\ 24044 Dalmine (BG), Italy \\ 2 UdR “Materials and Corrosion", Consorzio INSTM, Via Giusti 9, 50121 Florence, Italy \\ 3 UdR "Bergamo", Consorzio CSGI, Via della Lastruccia 3, 50019 Sesto Fiorentino, Italy \\ * Correspondence: denny.coffetti@unibg.it
}

Received: 23 March 2020; Accepted: 23 April 2020; Published: 27 April 2020

\begin{abstract}
The paper assesses the durability of one-part alkali-activated slag-based mortars (AAS) in different aggressive environments, such as calcium chloride- and magnesium sulphate-rich solutions, in comparison with traditional cementitious mortars at equal water to binder ratio. Moreover, the freezing and thawing resistance was evaluated on mortars manufactured with and without air entraining admixture (AEA). Experimental results indicate that the alkali content is a key parameter for durability of AAS: the higher the alkali content, the higher the resistance in severe conditions. In particular, high-alkali content AAS mortars are characterized by freeze-thaw resistances similar to that of blast furnace cement-based mixtures, but lower than that of Portland cement-mortars while AAS with low activators dosages evidence a very limited resistance in cold environment. The effectiveness of AEA in enhancement of freeze-thaw resistance is confirmed also for AAS mortars. Moreover, AAS mixtures are quasi-immune to expansive calcium oxychloride formation in presence of $\mathrm{CaCl}_{2}$-based deicing salts, but they are very vulnerable to magnesium sulphate attack due to decalcification of C-S-H gel and gypsum formation.
\end{abstract}

Keywords: alkali-activated materials; freezing and thawing resistance; sulphate attack; durability

\section{Introduction}

In the recent years, the research concerning the sustainability of cement and concrete industry has greatly increased both in academic and industrial community, following a three-sided approach aimed at reducing the environmental impact of cementitious materials, prolonging the service life of concrete structures and improving the performances of mixtures [1]. The alkali-activated slag-based materials (AAS) seem to be an effective solution to enhance the sustainability of concrete structures but their success is strictly related with their durability in aggressive environments. Only if the AAS was able to demonstrate adequate durability, their intensive use in the construction sector would be possible. Several studies were conducted in the field of rheology [2-4], physical performances [5-11] as well as microstructure [12-14] of AAS-based materials but only a limited number of paper concerning the durability of alkali-activated slag-based mortars and concretes was published. In particular, there are not papers that specifically deals with the topic of durability of one-part alkali-activated slag-based mixtures.

There is a relatively limited knowledge on resistance of AAS to sulphate attack. Immersion of two-parts alkali-activated slag binders in sodium sulphate solutions, according to traditional test method for Portland cement-based (OPC) concretes, does not promote expansion or cracking of binder paste $[15,16]$. On the contrary, OPC-based samples show significant expansion and cracking associated 
with the formation of secondary ettringite and gypsum [17]. Recent results [18] revealed that the key factor controlling the degradation mechanism of AAS is not the sulphate itself, as tends to be the case in Portland cement mixtures, but rather it is the nature of the cation accompanying the sulphate anion. Exposure to sodium sulphate seems to favor the structural evolution of the binding phases and densification of the system, which is consistent with the known role of $\mathrm{Na}_{2} \mathrm{SO}_{4}$ as activator. Conversely, the presence of magnesium leads to decalcification of the Ca-rich gel phases in alkali-activated materials, promoting the decay of the main binding phases and leading to formation of low-strength $\mathrm{M}-\mathrm{S}-\mathrm{H}$ type phases.

Resistance to freeze and thaw cycles is another important factor influencing the durability of concrete structures in cold regions and it depends mainly on the microstructure of hardened binder matrix (e.g., its porosity, pore size, capillaries, distribution, type of pores and spacing of entrained air bubbles). The deterioration of concrete structure in cold regions, that generally appears with internal cracks, expansions, surface scaling and mass loss, can be more pronounced in alkali-activated slag-based materials respect to Portland cement-based mixtures (OPC) due to the porous nature of AAS [19]. Nevertheless, only few papers investigated the freezing and thawing resistance of two-part AAS mixtures without additions (mineral or nano-addition). Fu et al. [20] evidenced a high freeze-thaw resistance of high performance AAS mortars although a comparison with OPC-based mortars is missing. Cai et al. [21] highlighted that the decisive factor influencing the freeze-thaw resistance is the air bubble spacing coefficient. However, the resistance to freeze and thaw could be increased by using air entraining agents, similarly to what is already done for OPC-based concretes.

Finally, no study was published concerning the resistance of AAS materials to calcium chloride-based deicing salts, both on one-part and two-part alkali-activated materials as defined by Luukkonen et al. [22].

The purpose of this study is to evaluate the durability of one-part alkali-activated slag-based mortars subjected to magnesium sulphate attack, exposed to freeze and thaw cycles or calcium chloride-based deicing salts in comparison with traditional cementitious mortars at equal water content. The effectiveness of an air entraining agent (AEA) on improving the resistance against freeze-thaw cycles was also investigated.

\section{Materials}

The one-part alkali-activated slag-based mortars were prepared by using a ground granulated blast furnace slag (GGBFS) with 28-day pozzolanic activity index equal to 0.76 (according to EN 196-5) as precursor and an alkaline powder as activator. In particular, a blend of sodium silicate, potassium hydroxide and sodium carbonate (all technical grade) with relative mass ratio of 7:3:1 was used as activator in accordance with previous studies [23,24]. Moreover, two different cement-based mortars were manufactured as reference by using a Type I Portland cement CEM I 42.5R (PC) and a CEM III/B $42.5 \mathrm{~N}$ blast furnace cement with high slag content (BFC), compliant with the EN 197-1 standard. The physical properties and the chemical composition of binders (Table 1) were investigated by means of laser granulometry (Mastersizer 3000 Malvern Instruments Ltd., Malvern, UK) and SEM-EDS measurements (Inspect, FEI Company, Hillsboro, OR, USA).

Table 1. Chemical composition and physical properties of binders.

\begin{tabular}{ccccccccccccc}
\hline \multicolumn{10}{c}{ Component wt.\% } & $\begin{array}{c}\text { Spec. Mass } \\
{\left[\mathbf{k g} / \mathbf{d m}^{3}\right]}\end{array}$ & $\begin{array}{c}\text { Spec. Surface } \\
{\left[\mathbf{m}^{2} / \mathbf{k g}\right]}\end{array}$ \\
\hline & $\mathbf{C a O}$ & $\mathbf{A l}_{\mathbf{2}} \mathbf{O}_{\mathbf{3}}$ & $\mathbf{S i O}_{\mathbf{2}}$ & $\mathbf{F e}_{\mathbf{2}} \mathbf{O}_{\mathbf{3}}$ & $\mathbf{S O}_{\mathbf{3}}$ & $\mathrm{TiO}_{\mathbf{2}}$ & $\mathbf{K}_{\mathbf{2}} \mathbf{O}$ & $\mathbf{M g O}$ & Others & & 350 \\
$\mathrm{PC}$ & 63.7 & 5.2 & 19.1 & 3.5 & 2.9 & 0.3 & 0.6 & 1.1 & 3.6 & 3.0 & 410 \\
$\mathrm{BFC}$ & 47.7 & 6.3 & 32.9 & 2.5 & 3.1 & 1.8 & 0.4 & 4.8 & 0.5 & 3.0 & 3.1 & 345 \\
\hline
\end{tabular}

The XRD pattern (Rigaku Miniflex 60, X-ray source Cu K-alpha 0.15418 nm, 40 kV, 15 mA, theta step 0.02 , rate $1 \% \mathrm{~min}$ ) of GGBFS reported in Figure 1 shows the typical amorphous hump 
around $2 \theta=25^{\circ}-35^{\circ}$ that reflects the short range order of $\mathrm{CaO}-\mathrm{Al}_{2} \mathrm{O}_{3}-\mathrm{MgO}-\mathrm{SiO}_{2}$ glass structure in accordance with [25]. Furthermore, the basicity coefficient $\mathrm{Kb}$ and the quality coefficient $\mathrm{Kq}$, calculated according to Wang et al. [26] starting from the chemical composition of GGBFS, were equal to 1.20 and 1.77 , respectively.

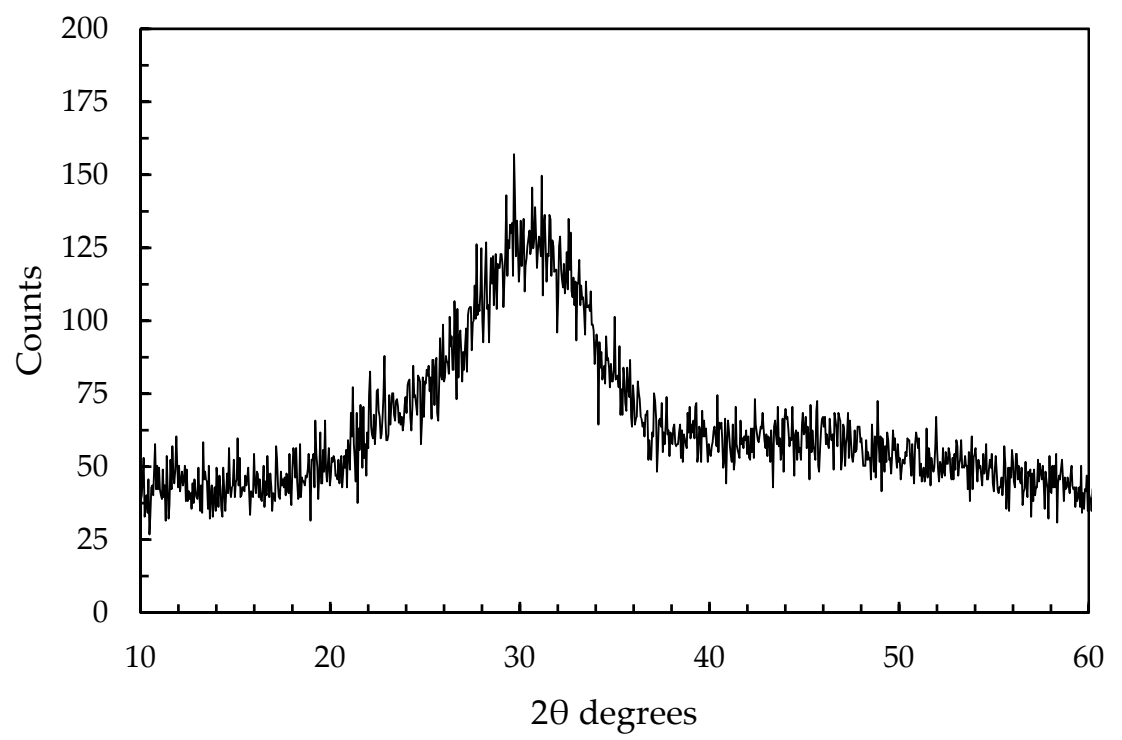

Figure 1. XRD pattern of GGBFS.

Five different natural siliceous sands (Table 2) with maximum size of $2.5 \mathrm{~mm}$ were used as aggregates. Finally, a superplasticizer based on ester of methacrylic acid monomer (PCE) having $1000 \mathrm{~g} / \mathrm{mol}$ side chain length and an acid/ester ratio equal to 3.5 and an air-entraining agent (AEA) based on cocamide diethanolamine (according to EN 934-2 and EN 480-2) were used.

Table 2. Physical properties of aggregates.

\begin{tabular}{|c|c|c|c|}
\hline Aggregate Size [mm] & Specific Mass $\left[\mathrm{kg} / \mathrm{dm}^{3}\right]$ & $\begin{array}{l}\text { Water Absorption s.s.d. } \\
\text { [wt.\%] }\end{array}$ & $\begin{array}{c}\text { Dosage }[w t . \% \text { vs Total } \\
\text { Aggregates] }\end{array}$ \\
\hline $0.00 / 0.25$ & 2.41 & 1.20 & 25 \\
\hline $0.25 / 0.50$ & 2.70 & 0.76 & 30 \\
\hline $0.50 / 1.00$ & 2.58 & 0.77 & 25 \\
\hline $1.00 / 1.50$ & 2.63 & 0.93 & 10 \\
\hline $1.50 / 2.50$ & 2.62 & 1.02 & 10 \\
\hline
\end{tabular}

\section{Mixture, Preparation and Samples Curing}

Three one-part alkali-activated slag-based mortars were prepared at equal silica modulus $(\mathrm{Ms}=0.48)$ by varying the alkali content $(\mathrm{Ac})$ between 0.038 and 0.075 [27]. In addition, two cementitious mortars manufactured with Portland cement (PC) or blast furnace cement (BFC) were used as control mixtures. In all mixes, the water/binder $(\mathrm{w} / \mathrm{b})$ and the sand/binder $(\mathrm{s} / \mathrm{b})$ of mortars were fixed at 0.55 and 3.00, respectively. Furthermore, in order to ensure a thixotropic consistency of cement-based mortars, a superplasticizer was used at $0.5 \mathrm{wt} . \%$ vs. cement mass.

Finally, a second set of mortars were prepared by using the air-entraining agent in order to achieve an air content equal to $10 \pm 1 \%$ in order to evaluate the effectiveness of AEA to enhance the freeze/thaw resistance of one-part AAS. Details on the mix composition are listed in Table 3.

Cement-based mortars were manufactured according to EN 196-1 while AAS mixtures were prepared in accordance with the "Dry mixing method" reported in [28] and already used in previous studies $[24,29]$. In particular, the procedure is composed by five phases:

(i) GGBFS, alkali activator in solid form and tap water are placed into the steel bowl; 
(ii) The mixer starts at low speed (140 rpm for the revolving action, $62 \mathrm{rpm}$ for the planetary action) for $30 \mathrm{~s}$;

(iii) The mixing proceeds at high speed (285 rpm for the revolving action, $125 \mathrm{rpm}$ for the planetary action) for $60 \mathrm{~s}$;

(iv) The mixture rests for $90 \mathrm{~s}$;

(v) The mixer completes the procedure with further $60 \mathrm{~s}$ at high speed.

Prismatic specimens $40 \mathrm{~mm} \times 40 \mathrm{~mm} \times 160 \mathrm{~mm}$ were cast and kept in laboratory conditions for $24 \mathrm{~h}\left(20 \pm 2{ }^{\circ} \mathrm{C}\right)$. Then, the specimens were removed from the steel mold, rinsed in water and cured in a climatic chamber $\left(20 \pm 2{ }^{\circ} \mathrm{C}, 60 \pm 5 \%\right.$ R.H. $)$ till the time of experiment.

Table 3. Composition of mortars. PC: Portland cement-based mortars; BFC: Blast furnace cement-based mortars; AAS: Alkali-activated slag-based mortars (the number indicates the activator to slag ratio by mass); AE: mortars containing AEA.

\begin{tabular}{cccccc}
\hline Composition [g] & $\begin{array}{c}\text { PC } \\
\text { PC_AE }\end{array}$ & $\begin{array}{c}\text { BFC } \\
\text { BFC_AE }\end{array}$ & $\begin{array}{c}\text { AAS8 } \\
\text { AAS8_AE }\end{array}$ & $\begin{array}{c}\text { AAS12 } \\
\text { AAS12_AE }\end{array}$ & $\begin{array}{c}\text { AAS16 } \\
\text { AAS16_AE }\end{array}$ \\
\hline PC & 450 & & & & \\
BFC & & 450 & & & \\
GGBFS & & & 450 & 450 & 450 \\
Activators & 1350 & 1350 & 1350 & 1350 & 72 \\
Aggregates & 225 & 225 & 225 & 225 & 225 \\
Water & 2.25 & 2.25 & & & \\
Superplasticizer & 0 & 0 & 0 & 0 & 0 \\
Air entraining agent & 0.140 & 0.125 & 0.225 & 0.200 & 0.160 \\
Water/binder & 0.55 & 0.55 & 0.55 & 0.55 & 0.55 \\
Aggregates/binder & 3.00 & 3.00 & 3.00 & 3.00 & 3.00 \\
\hline
\end{tabular}

\section{Experimental Methods}

\subsection{Fresh State and Elasto-Mechanical Properties}

After the mixing, the workability was measured on mortars by means of a flow table (EN 1015-3), the specific mass was evaluated at fresh state according to EN 1015-6 and the air content was detected in accordance with EN 1015-7. Specific mass at hardened state, flexural and compressive strength were determined at 1, 7, 28, 56 and 84 days from casting (EN 1015-11). Furthermore, dynamic modulus of elasticity of mortars was estimated by means of Ultrasonic Digital Indicator Tester at 28 days in accordance with EN 12504-4.

\subsection{Freezing and Thawing Resistance}

The freeze-thaw cycles resistance of AAS manufactured with and without AEA was evaluated according to the Italian Standard UNI 7087 (minimum temperature $-20^{\circ} \mathrm{C}$, maximum temperature $+5^{\circ} \mathrm{C}$, cooling speed $-4.5^{\circ} \mathrm{C} / \mathrm{h}$, cycle time of $12 \mathrm{~h}$ ) measuring the mass change, the compressive strength loss and the elastic modulus variations every 25 cycles up to 150 cycles. The experimental test was performed on mortar samples cured for 28 days at $20^{\circ} \mathrm{C}$ and R.H. $60 \%$.

\subsection{Calcium Chloride Resistance}

The attitude to the formation of the expansive compound (calcium oxychloride) of AAS in $\mathrm{CaCl}_{2}$-based deicing salts-rich solutions was investigated. Mortar specimens were cured for 28 days in a climatic chamber at $20^{\circ} \mathrm{C}$ and $60 \%$ R.H., were subsequently stored for 28 days in a $30 \mathrm{wt} . \% \mathrm{CaCl}_{2}$ solution at $38{ }^{\circ} \mathrm{C}$ to promote the calcium chloride ingress in the matrix, and finally were cooled at $4{ }^{\circ} \mathrm{C}$ in order to enhance the expansive compound formation as a consequence of reaction between calcium chloride, lime and water [30]. The durability was evaluated as mass change and strength loss 
compared with mortars stored in deionized water following the same thermal cycle $\left(20^{\circ} \mathrm{C}\right.$ for 28 days, $38^{\circ} \mathrm{C}$ for 28 days and then cooled at $4{ }^{\circ} \mathrm{C}$ ).

\subsection{Magnesium Sulphate Attack Resistance}

After 28-day curing at $20^{\circ} \mathrm{C}$ and R.H. $60 \%$, the prismatic specimens were partially immersed in $10 \mathrm{wt} . \% \mathrm{MgSO}_{4}$ solution. The efflorescence formation was monitored every 7 days up to 130 days, then the degradation of cementitious matrix was determined by measuring both the mass of efflorescence and the strength loss of specimens in different areas (totally immersed in the solution, exposed to air and close to the free surface of solution) as reported in Figure 2.

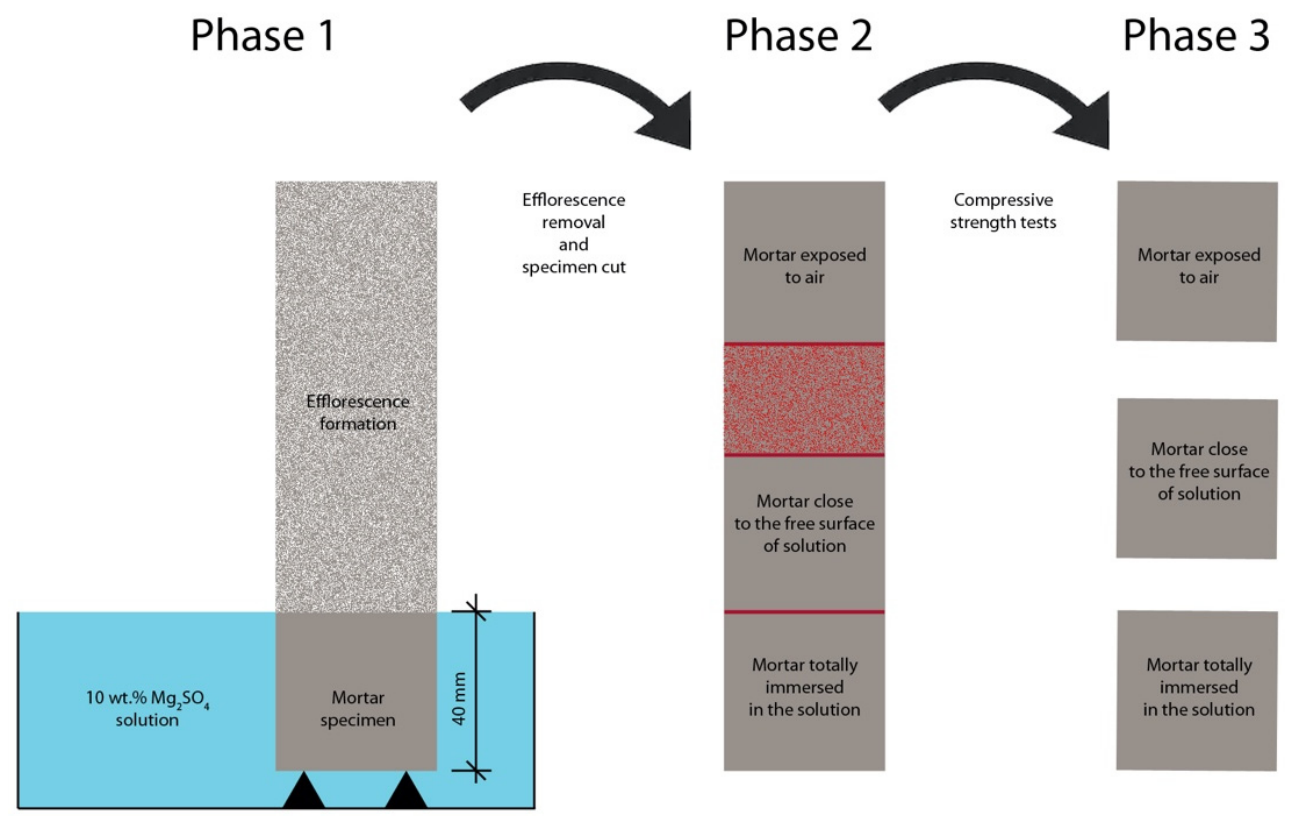

Figure 2. Schematic procedure for evaluating the durability of mortars in sulphate-rich aqueous solution.

\section{Results and Discussion}

\subsection{Fresh State and Elasto-Mechanical Properties}

The mortars manufactured without AEA present a thixotropic consistency with a workability by flow table ranging from 150 and $190 \mathrm{~mm}$ (Table 4). Moreover, as expected, the workability of AAS mortars increases by increasing the alkali content due to the deflocculating and plasticizing effect promoted by the use of sodium silicate as activator that reduce the yield stress at early ages $[2,10]$.

The addition of the AEA determines an increase of workability of about $50 \%$ both in cementitious and alkali-activated mortars (Table 5) due to the spherical air bubbles that act as a fine aggregate of very low surface friction. The air content and the specific mass at fresh state of mortars without AEA are similar, generally close to $5 \%$ and $2150 \mathrm{~kg} / \mathrm{m}^{3}$, respectively. On the contrary, the 28-day specific mass of AAS8 is $110 \mathrm{~kg} / \mathrm{m}^{3}$ lower than that of AAS16, probably due to the smaller degree of reaction of slag and higher free water content as reported by Coffetti [31]. As reported in Table 3, the effectiveness of AEA in the air-entrained mortars varies depending on the nature of the binder (PC and BFC require less admixture respect to AAS mortars) and the Ac of alkali-activated mortars (by increasing the Ac, the dosage of AEA to obtain an air content close to $10 \%$ decrease up to $40 \%$ ). 
Table 4. Fresh and hardened properties of mortars manufactured without AEA.

\begin{tabular}{|c|c|c|c|c|c|c|}
\hline & & PC & BFC & AAS8 & AAS12 & AAS16 \\
\hline \multicolumn{2}{|l|}{ Workability [mm] } & 150 & 160 & 165 & 180 & 190 \\
\hline \multicolumn{2}{|c|}{ Entrapped air $[\%]$} & 5.0 & 5.2 & 4.7 & 4.5 & 4.0 \\
\hline \multicolumn{2}{|c|}{ Specific mass at fresh state $\left[\mathrm{kg} / \mathrm{m}^{3}\right]$} & 2140 & 2140 & 2150 & 2150 & 2165 \\
\hline \multicolumn{2}{|c|}{ Specific mass at hardened state $\left[\mathrm{kg} / \mathrm{m}^{3}\right]$} & 2110 & 2100 & 2010 & 2090 & 2120 \\
\hline \multirow{5}{*}{ Flexural strength $[\mathrm{MPa}]$} & 1 day & 4.9 & 3.0 & 0.3 & 2.5 & 2.7 \\
\hline & 7 days & 6.8 & 4.3 & 2.1 & 2.7 & 3.0 \\
\hline & 28 days & 9.1 & 6.7 & 2.7 & 3.1 & 3.4 \\
\hline & 56 days & 9.2 & 6.8 & 2.7 & 3.2 & 3.4 \\
\hline & 84 days & 9.3 & 7.0 & 2.9 & 3.8 & 3.5 \\
\hline \multirow{5}{*}{ Compressive strength [MPa] } & 1 day & 27.8 & 12.4 & 1.1 & 9.4 & 10.9 \\
\hline & 7 days & 46.5 & 31.5 & 15.4 & 25.5 & 30.2 \\
\hline & 28 days & 47.7 & 43.1 & 18.1 & 34.0 & 39.1 \\
\hline & 56 days & 48.1 & 44.2 & 19.0 & 35.0 & 40.2 \\
\hline & 84 days & 48.3 & 44.7 & 19.4 & 35.8 & 41.3 \\
\hline \multicolumn{2}{|c|}{ 28-day elastic modulus [GPa] } & 32.8 & 30.2 & 20.9 & 24.9 & 27.9 \\
\hline
\end{tabular}

Table 5. Fresh and hardened properties of mortars manufactured with AEA.

\begin{tabular}{|c|c|c|c|c|c|c|}
\hline & & PC_AE & BFC_AE & AAS8_AE & AAS12_AE & AAS16_AE \\
\hline \multicolumn{2}{|l|}{ Workability [mm] } & 180 & 185 & 210 & 220 & 220 \\
\hline \multicolumn{2}{|c|}{ Entrapped air $[\%]$} & 11.0 & 11.0 & 10.5 & 10.0 & 11.0 \\
\hline \multicolumn{2}{|c|}{ Specific mass at fresh state $\left[\mathrm{kg} / \mathrm{m}^{3}\right]$} & 2000 & 2010 & 2020 & 2020 & 2010 \\
\hline \multicolumn{2}{|c|}{ Specific mass at hardened state $\left[\mathrm{kg} / \mathrm{m}^{3}\right]$} & 1950 & 1950 & 1970 & 1980 & 1980 \\
\hline \multirow{5}{*}{ Flexural strength [MPa] } & 1 day & 3.2 & 1.9 & 0.2 & 1.8 & 1.9 \\
\hline & 7 days & 5.7 & 3.1 & 1.2 & 2.1 & 2.5 \\
\hline & 28 days & 7.8 & 5.0 & 1.8 & 2.5 & 2.9 \\
\hline & 56 days & 8.0 & 5.2 & 2.0 & 2.9 & 3.0 \\
\hline & 84 days & 8.0 & 5.8 & 2.1 & 3.0 & 3.2 \\
\hline \multirow{5}{*}{ Compressive strength [MPa] } & 1 day & 19.4 & 8.0 & 0.8 & 5.6 & 7.2 \\
\hline & 7 days & 39.1 & 26.3 & 12.5 & 19.3 & 25.4 \\
\hline & 28 days & 41.2 & 36.3 & 13.4 & 22.6 & 30.2 \\
\hline & 56 days & 42.1 & 37.0 & 14.1 & 25.1 & 32.1 \\
\hline & 84 days & 42.5 & 37.9 & 15.0 & 27.0 & 33.5 \\
\hline \multicolumn{2}{|c|}{ 28-day elastic modulus [GPa] } & 28.1 & 27.0 & 17.9 & 21.6 & 25.9 \\
\hline
\end{tabular}

Concerning the compressive strength measured on prismatic specimens (Tables 4 and 5), it is possible to note that by growing the alkali content, the strength increases regardless of age due to the higher $\mathrm{pH}$ of activating solution that promotes the dissolution of silica and alumina of GGBFS [26] and the formation of a denser microstructure [31]. In particular, after 28 days, AAS8 reaches a strength class of $20 \mathrm{MPa}$, AAS12 of $35 \mathrm{MPa}$ and AAS 16 of $40 \mathrm{MPa}$ while PC shows strength close to $48 \mathrm{MPa}$ and BFC is characterized by a compressive strength of $43 \mathrm{MPa}$. Furthermore, it is evident that the flexural strength and the elastic modulus of elasticity of cement-based mixtures are generally higher than those of AAS mortars, mainly due to the micro-cracks formation related to the high shrinkage of alkali-activated materials [32,33]. The influence of AEA addition on the compressive strength of mortars was evaluated by means of coefficient $\eta$ at different ages calculated as the ratio between the strength of air-entrained mortar and the mixture manufactured without AEA. Results reported in Figure 3 evidence a delay in the strength development at $24 \mathrm{~h}$ ( $\eta$ is in the range $60 \%-70 \%$ for all mixes) while the strength of the air-entrained mixtures at late ages is about $75 \%$ for alkali-activated mortars and $85 \%$ for cementitious mortars with respect to the mixtures manufactured without AEA. 


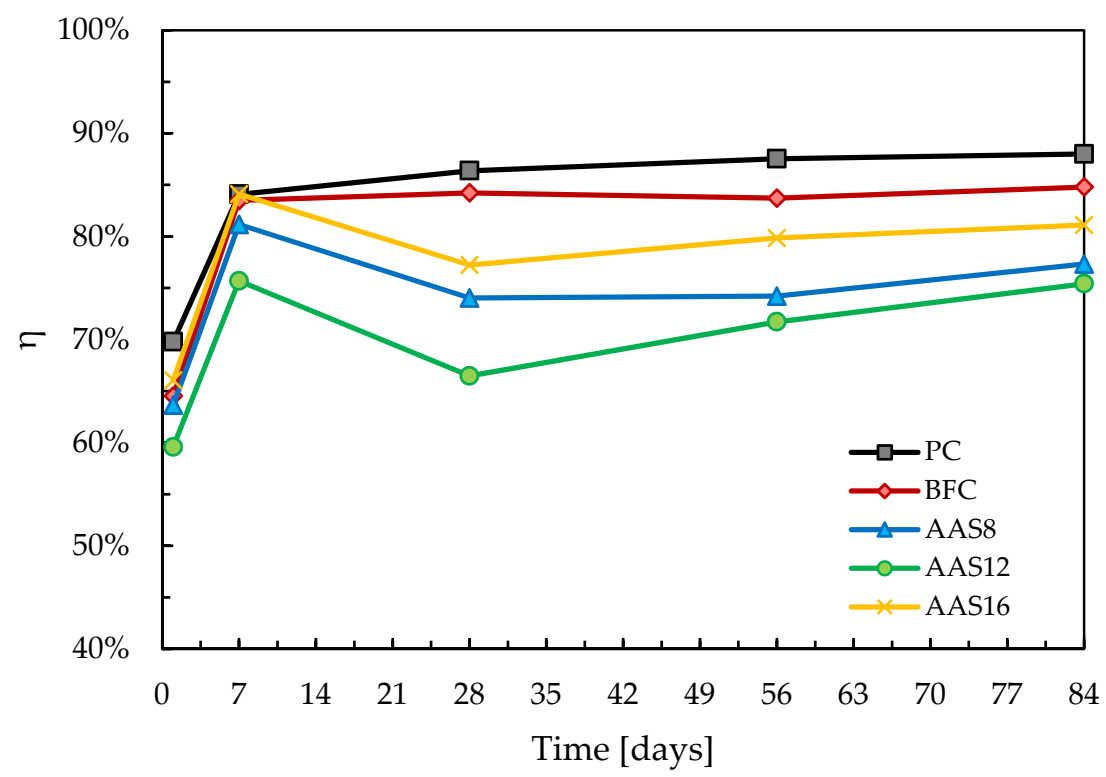

Figure 3. Ratio $\eta$ between the compressive strengths of air-entrained mortars and mixtures produced without AEA at different ages.

\subsection{Freezing and Thawing Resistance}

The visual observation of specimens subjected to freeze and thaw cycles highlights a strong superficial deterioration of AAS8 and AAS8_AE mortars already after 50 cycles while the other alkali-activated mortars (AAS12 and AAS16) and the cement-based mortars (PC and BFC) are characterized by minor damages or appear intact at the end of 150 cycles, regardless of the addition of AEA (Figure 4).

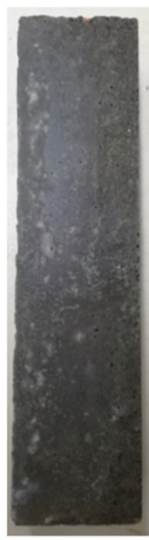

PC

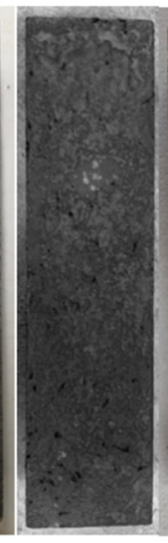

PC_AE

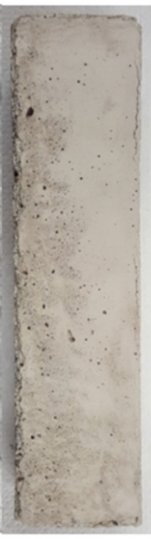

$\mathrm{BFC}$
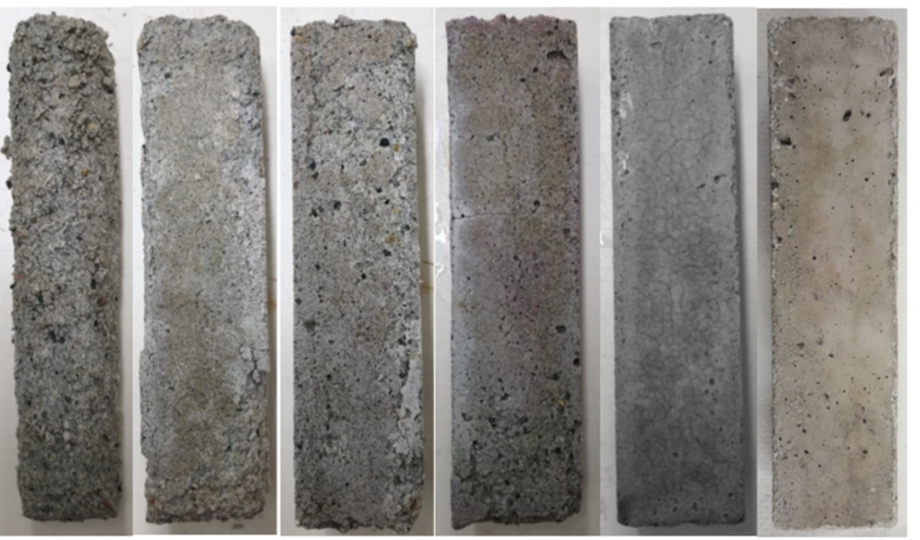

Figure 4. Superficial deterioration of specimens after 150 cycles.

The superficial deterioration of AAS8 is combined with a pronounced mass loss that reaches $2 \%$ after 75 cycles and achieves $12 \%$ at the end of test that corresponds to a reduction in the specimen size of about 3-4 mm. On the contrary, the mass change after 150 cycles is close to zero for all the other non-admixed samples (Figure 5). The addition of the AEA promotes a strong enhancement in the freezing and thawing resistance of AAS8_AE with a reduction of the mass loss at the end of the freeze/thaw cycles approximately by half. However, the mass loss of this mixture, despite the addition of the AEA, is very high due to its poor mechanical properties. 


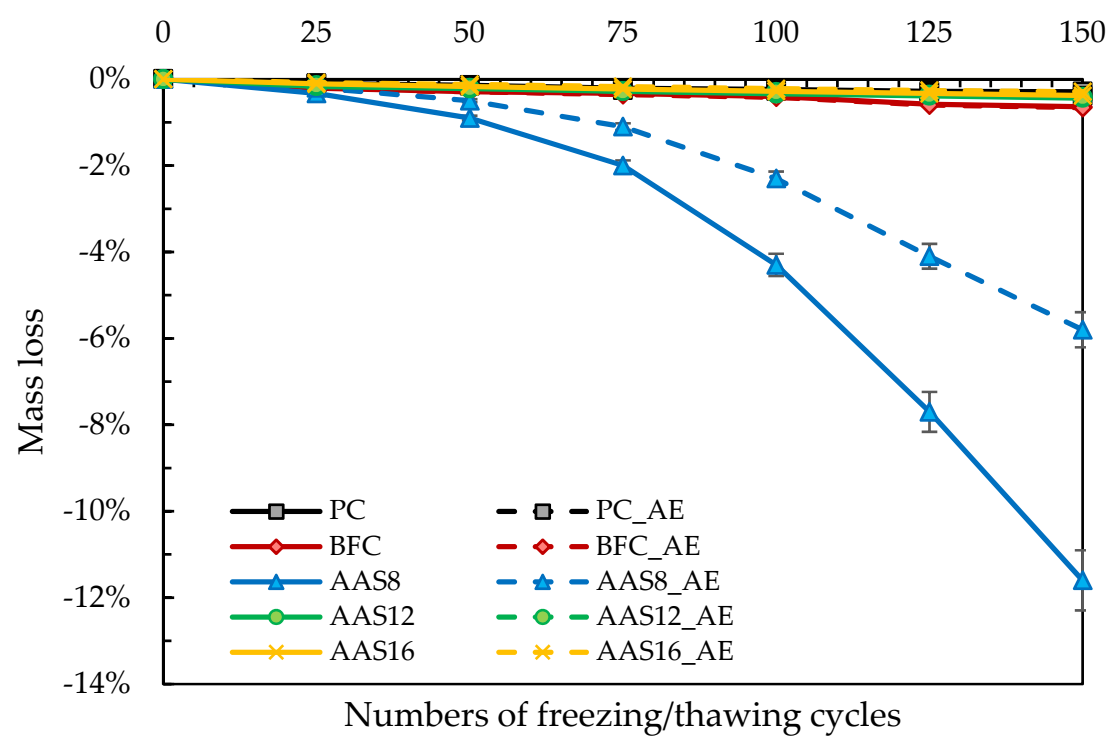

Figure 5. Mass loss of mortars as a function of numbers of freezing/thawing cycles.

In Figure 6 is reported the strength loss of mortars over time with respect to specimens cured at $20^{\circ} \mathrm{C}$. Results indicate that PC samples are not affected by compressive strength variation, BFC, AAS12 and AAS16 worsen their mechanical performances by about $25 \%-30 \%$ while alkali-activated mortar AAS8 shows strength loss of 70\% after 150 cycles. The mortars manufactured with the addition of AEA show a greater resistance to freezing and thawing cycles, with strength loss strongly reduced respect to the non-admixed mortars. In particular, by the addition of the AEA, the AAS8_AE reduces the compressive strength loss from $67 \%$ to $45 \%$, the AAS12_AE from $30 \%$ to $22 \%$, the AAS16_AE from $25 \%$ to $18 \%$ and the BFC_AE from $26 \%$ to $14 \%$. No significant variations were detected in Portland cement-based mortars.

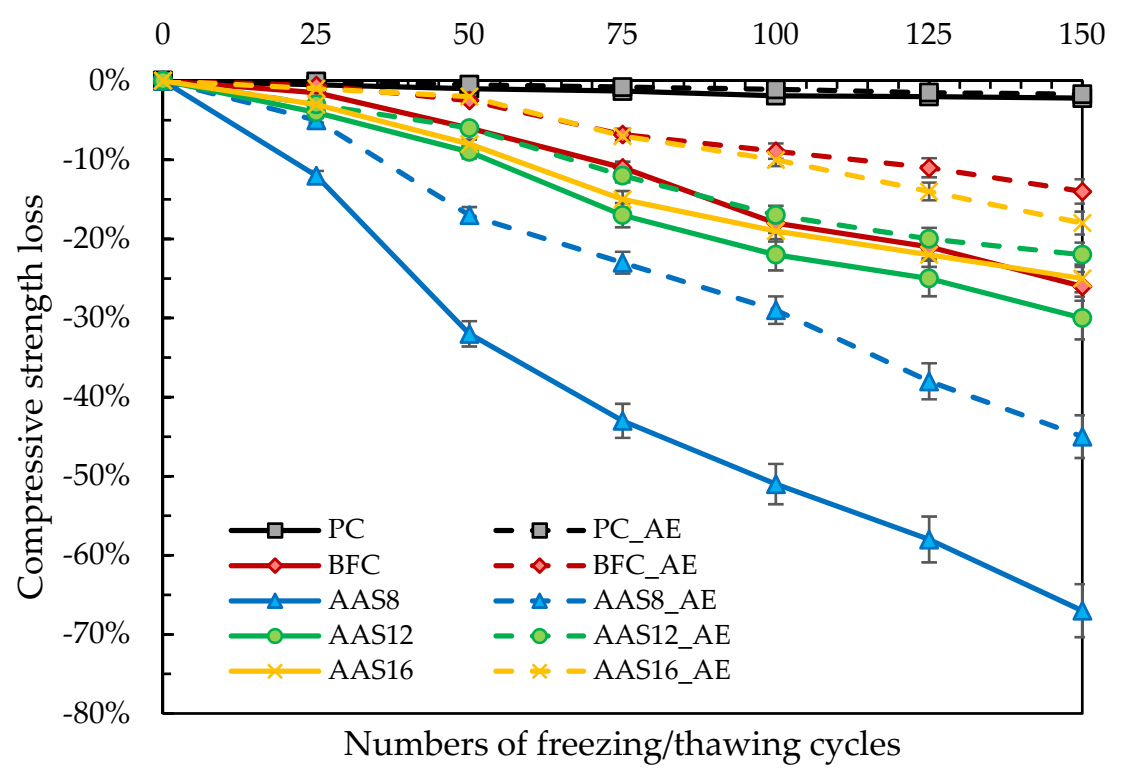

Figure 6. Strength loss of mortars as a function of numbers of freezing/thawing cycles.

Nevertheless, Fu et al. [20] claim that it is improper to set the mass change and the strength loss of alkali-activated materials as index of freeze and thaw destroy, suggesting to evaluate the dynamic modulus of elasticity to estimate the freeze and thaw resistance of AAS.

Experimental results reported in Figure 7 show that with increase of freeze and thaw cycle times, elastic modulus of elasticity of PC decrease extremely slowly (less than 10\% after 150 cycles), evidence 
of excellent durability, while BFC and AAS loose approximately $25-30 \%$ of dynamic modulus of elasticity at the end of test. Alkali-activated mortar AAS8 is an exception because it shows an extremely marked stiffness loss (60\% after 150 cycles), consistently with the mass change and the strength loss reported in previous figures. The use of AEA determines a reduction of stiffness loss for all mixes up to $50 \%$, in accordance with the other results reported in the paragraph. Moreover, by measuring the dynamic modulus of elasticity it is possible to appreciate the role of the air entraining admixture in the improvement in the freeze/thaw resistance of Portland cement-based mortar, with a reduction in stiffness loss from $7 \%$ (PC) to $2.2 \%$ (PC_AE).

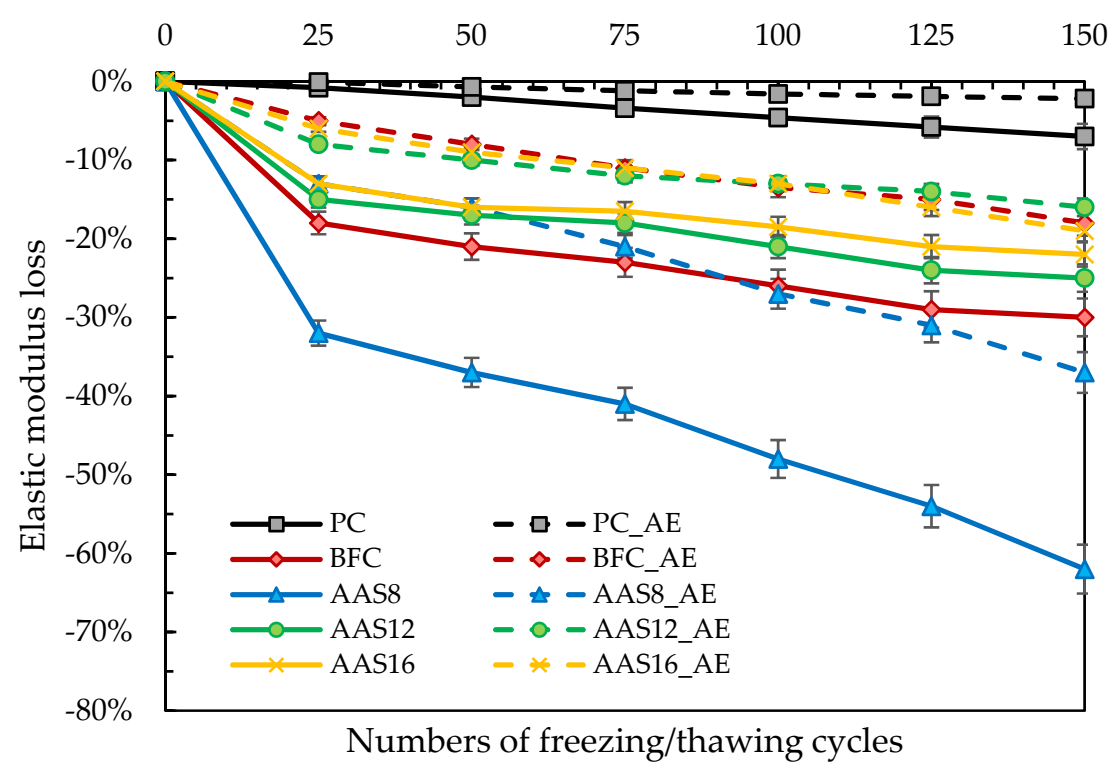

Figure 7. Elastic modulus loss of mortars as a function of numbers of freezing/thawing cycles.

The different behavior between the non-admixed mortars is primarily attributable to the compactness of matrix. In fact, according to Shahrajabian and Behfarnia [34], low compactness of the mortars promotes the water penetration, freezing and saturation, thereby reducing the durability against freeze and thaw cycles. This is confirmed by optical microscopy observation on AAS8 sample (before the freeze and thaw cycles) that highlights a low-density structure with micro-cracks and air void ranging from 20 and $200 \mu \mathrm{m}$ (Figure 8).

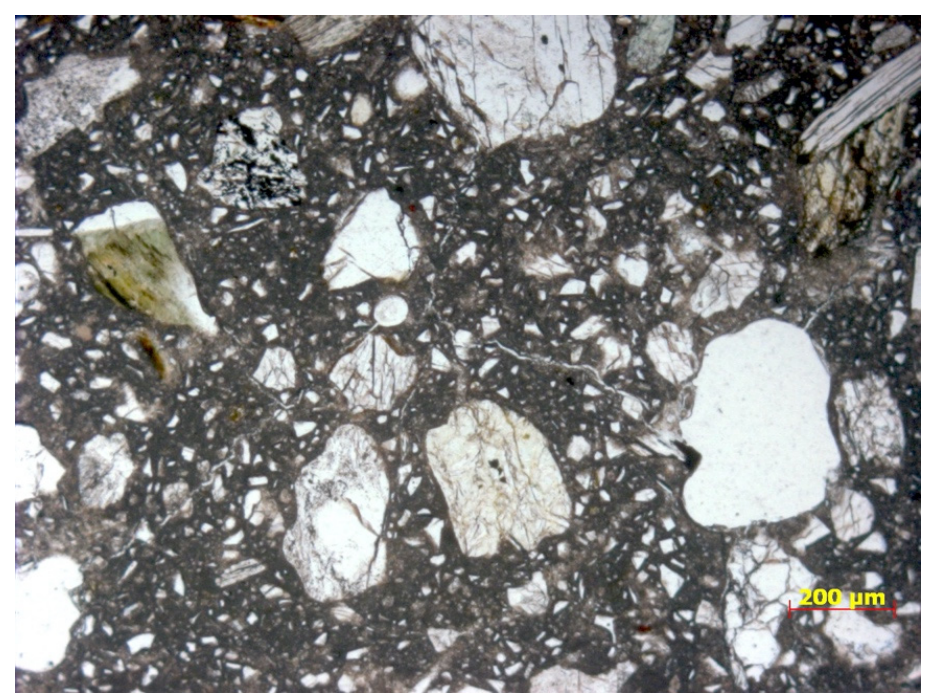

Figure 8. Optical microscopy observation of AAS8 before freeze/thaw cycles. 


\subsection{Calcium Chloride Resistance}

The visual examination was regularly made (every 2 days) to assess the conditions of the specimens. Micro-cracks along the edges and separation of the surface layer from the core of the specimens are the main damages detected on PC mortars (Figure 9). Also, the mass loss and the strength loss are very pronounced (Figures 10 and 11), reaching values close to $2 \%$ and $40 \%$, respectively, already after 7 days at $4{ }^{\circ} \mathrm{C}$. On the contrary, BFC and AAS samples appear unaltered without significant mass changes and strength loss lower than $8 \%$.

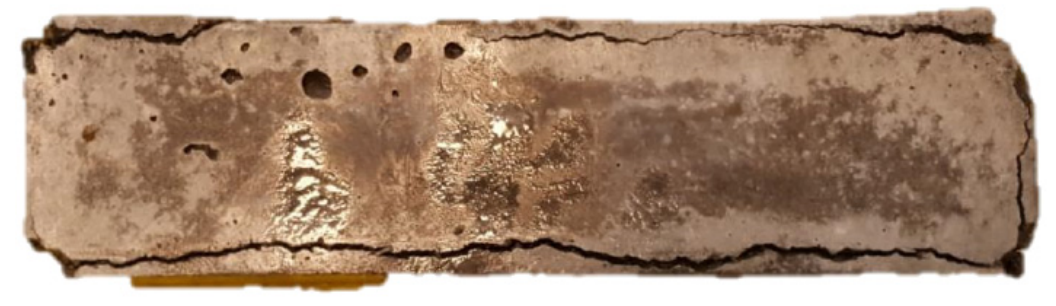

Figure 9. PC specimen after 42 days in $\mathrm{CaCl}_{2}$-rich solution.

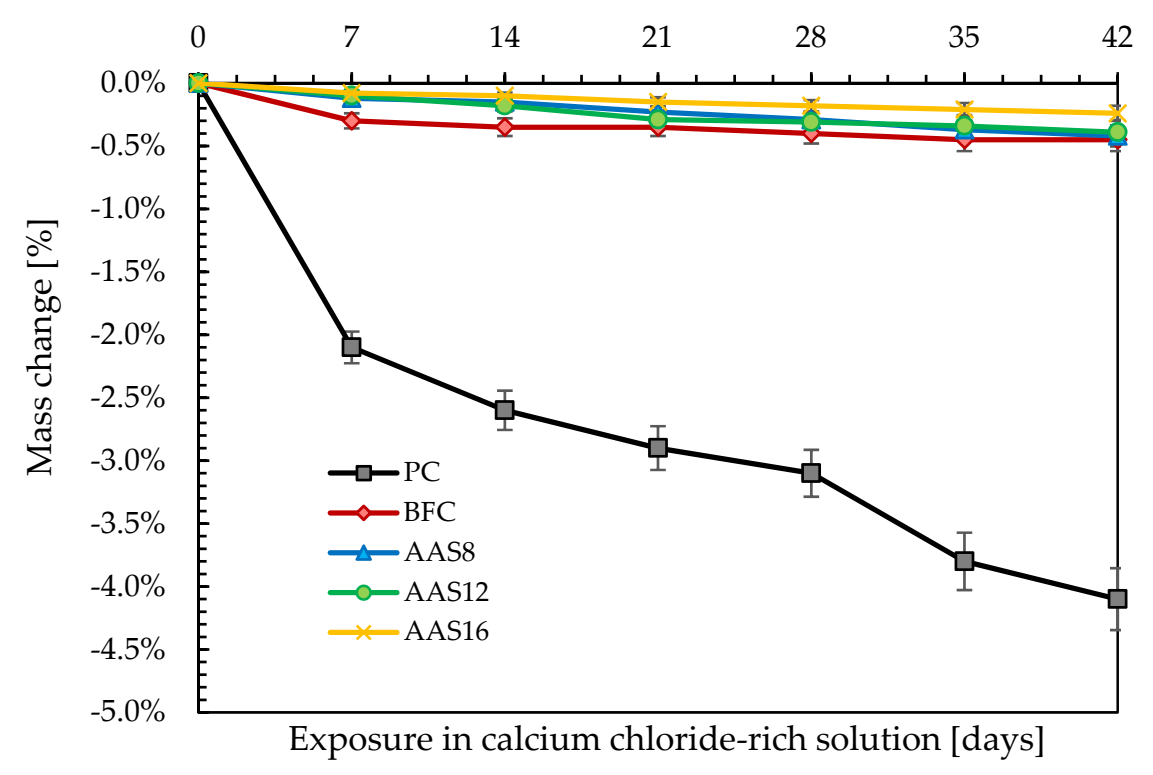

Figure 10. Mass change of specimens exposed to $\mathrm{CaCl}_{2}$-rich solution.

This behavior could be related to the calcium hydroxide content of alkali-activated mixtures and cement mortars. In fact, the reaction can occur between the calcium hydroxide in the matrix, the calcium chloride in the deicing salt and the water as reported in Equation (1):

$$
3 \mathrm{Ca}(\mathrm{OH})_{2}+\mathrm{CaCl}_{2}+12 \mathrm{H}_{2} \mathrm{O} \rightarrow \mathrm{CaCl}_{2} \cdot 3 \mathrm{Ca}(\mathrm{OH})_{2} \cdot 12 \mathrm{H}_{2} \mathrm{O}
$$

The higher the amount of $\mathrm{Ca}(\mathrm{OH})_{2}$, the greater the calcium oxychloride formation [35]. As well known, in the Portland cement-based mixtures, one of the main hydration products is the calcium hydroxide which is therefore widely available for the reaction with calcium chloride. On the other hand, the pozzolanic reaction involving the blast furnace cements promotes the transformation of calcium hydroxide into calcium silicate hydrate (C-S-H) and calcium aluminate hydrate (C-A-H), severely limiting the oxychloride formation due to the reagent shortage. Previous research by Coffetti [31] and studies of Myers et al. [36,37] highlighted that the calcium hydroxide in the reaction products of AAS produced with high calcium GGBFS are totally missing or very limited. For this reason, the use of alkali-activated slag-based binders instead of Portland cement could strongly enhance the durability of mortars and concretes exposed to calcium chloride-based deicing salts. 


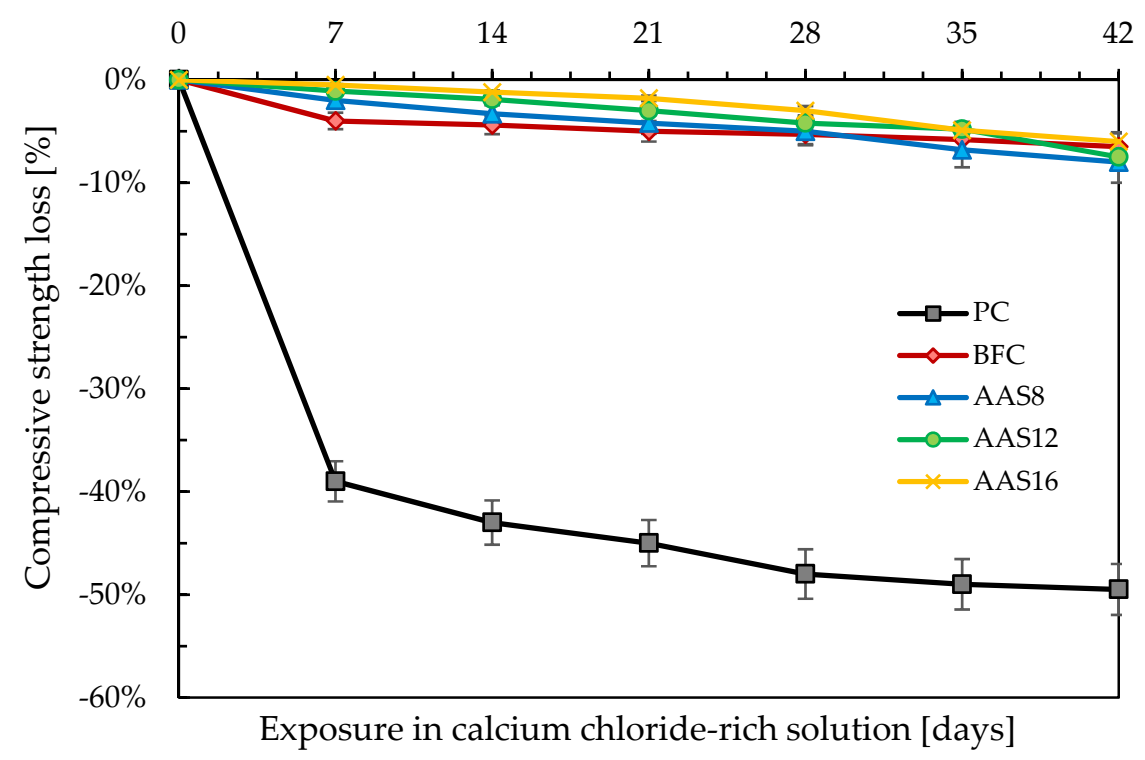

Figure 11. Compressive strength loss of specimens exposed to $\mathrm{CaCl}_{2}$-rich solution.

\subsection{Magnesium Sulphate Attack Resistance}

The partial immersion of specimens in magnesium sulphate-rich solution promotes the development of whitish efflorescence combined with an intense deterioration of AAS mortars close to the free surface of solution (Figure 12).

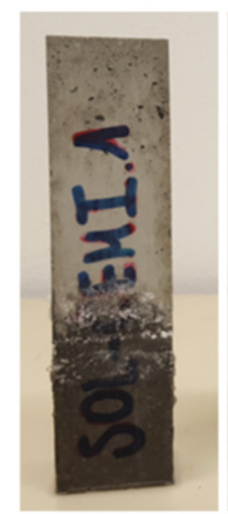

PC

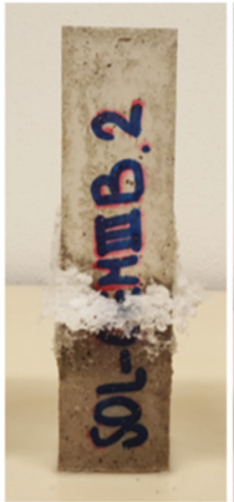

BFC

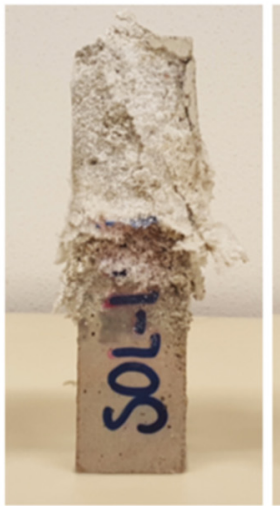

AAS8

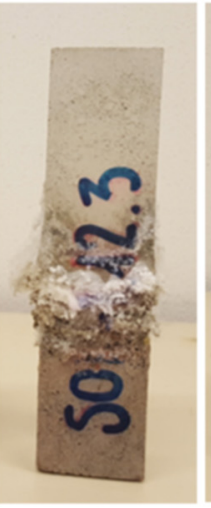

AAS12

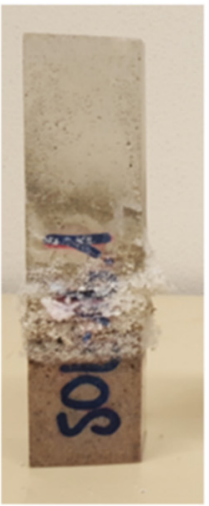

AAS16

Figure 12. Efflorescence formation after 130 days in sulphate-rich solution.

Moreover, the amount of efflorescence is strictly related to the compactness of matrix and is inversely proportional to the alkali content of mortars: the higher the alkali content, the lower the efflorescence volume (Figure 13). On the contrary, PC samples are almost efflorescence-free while BFC specimens are characterized by an efflorescence formation similar to that of AAS16.

The evaluation of compressive strength after the sulphate attack evidences the vulnerability of activated alkali systems. As reported in Figure 14, negligible deterioration (PC, BFC and AAS16 show compressive strength unaltered) or very limited damages (AAS8 and AAS12 reduce their strength of about $5 \%-10 \%$ ) were detected in the areas totally immersed in the $\mathrm{MgSO}_{4}$ solution while areas subjected to the efflorescence formation show strength loss that reach values up to $60 \%$ for AAS mortars while cement-based mixtures reduce their strength of about $15 \%-25 \%$ after sulphate exposure. 


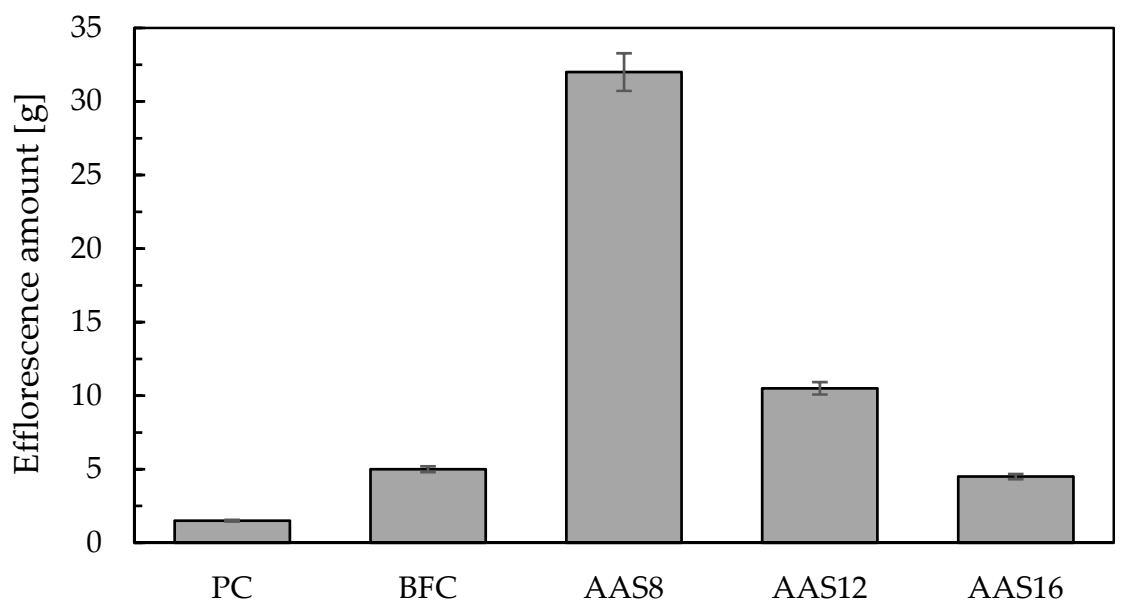

Figure 13. Efflorescence amount after 130 days in sulphate-rich solution.

The degradation in these areas could be ascribed to the effect of the sulphate attack (formation of expansive products such as ettringite and gypsum) in combination with the deteriorating effect of the recrystallization of the sulphate salts in the mortar pores as a consequence of the evaporation of the water absorbed by the specimens by capillary. In particular, as reported by Bakharev et al. [15] and Ismail et al. [18], the mechanisms of ettringite and gypsum formation are important in sulphate attack on Portland cement-based mortars while the deterioration of AAS under sulphate attack is associated with decalcification of C-S-H gel, responsible for the precipitation of gypsum and the reduction of the binding capacity of the pastes. Moreover, also the porosity of mortars and the calcium hydroxide $(\mathrm{CH})$ content influence the sulphate resistance of alkali-activated mixtures and cementitious mortars. In fact, high $\mathrm{CH}$ contents promote the formation of gypsum as a consequence of reaction with sulphate ions. Blast furnace cements and alkali-activated materials present limited or negligible calcium hydroxide content $[17,31]$ and they are potentially very resistant to sulphates. On the other hand, the lower mechanical strengths of the AAS8 to Portland cement-based mortars are strictly correlated with high porosity of mortars and thus with a high permeability that limited resistance in $\mathrm{SO}_{4}$-rich environments.

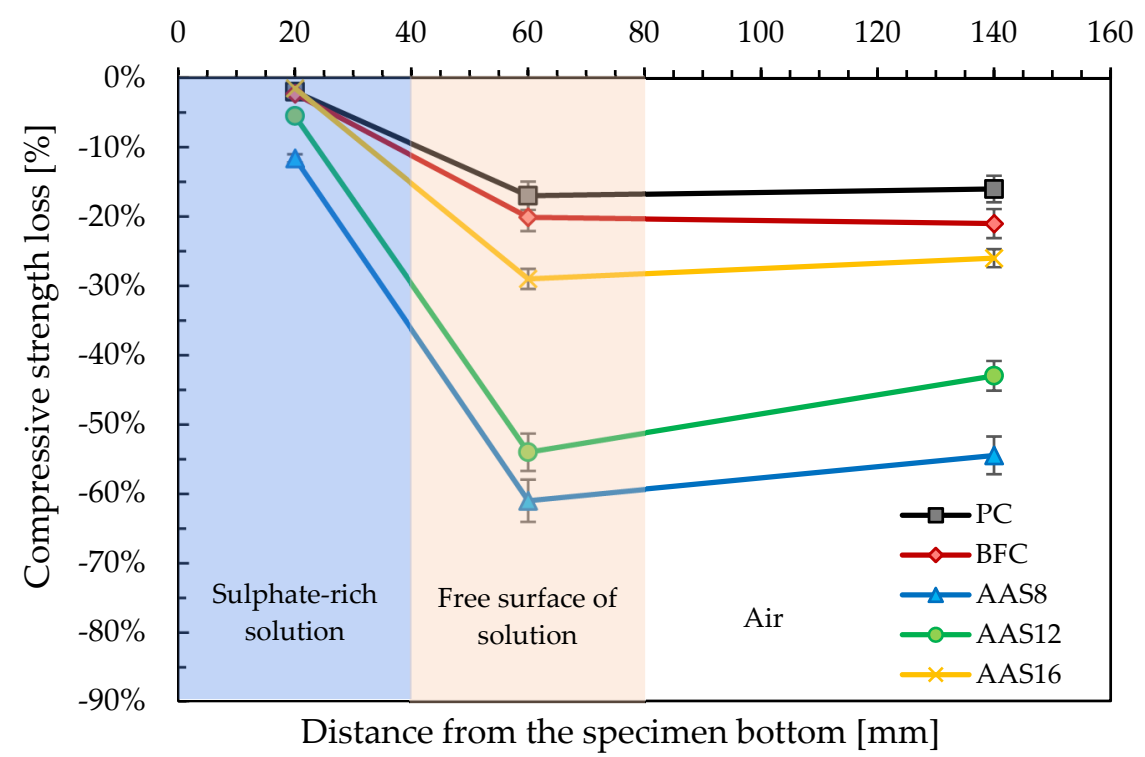

Figure 14. Compressive strength loss after 130 days in sulphate-rich solution. 


\section{Conclusions}

This experimental study was aimed at evaluating the durability of one-part alkali-activated slag-based mortars in different severe environments in comparison with traditional cementitious mortars. The following conclusions can be drawn:

- The alkali content plays a crucial role both in elasto-mechanical properties and in durability performances of alkali-activated materials. In general, the higher the alkali content, the higher the strength and the resistance in severe conditions;

- High-alkali content AAS mortars evidenced a freeze-thaw resistance similar to that of BFC mortars but lower than that of PC-probably due to the different compactness of AAS matrix respect to Portland cement mortars at equal water content. On the contrary, AAS manufactured with low dosages of activators are characterized by a very limited resistance in cold environments;

- The use of AEA enhances the freezing and thawing resistance of alkali-activated slag-based mortars without any strong reduction in compressive strength;

- Similarly to BFC, alkali-activated mixtures are quasi-immune to expansive calcium oxychloride formation in presence of $\mathrm{CaCl}_{2}$-based deicing salts due to the negligible calcium hydroxide content;

- Alkali-activated slag-based mortars suffer from severe damages and high strength loss as a consequence of semi-immersion in $10 \mathrm{wt} . \% \mathrm{Mg}_{2} \mathrm{SO}_{4}$ solution due to decalcification of C-S-H gel and gypsum formation.

Author Contributions: Conceptualization and methodology, all authors; analyzing and testing, D.C.; E.C., G.G.; writing—original draft preparation, D.C.; writing—review and editing, L.C., D.C., E.C., G.G.; supervision, L.C. and T.P. All authors have read and agreed to the published version of the manuscript.

Funding: This research received no external funding.

Acknowledgments: Authors want to thank Eng. Valentina Bassetti, Eng. Maria Elena Cornelli and Eng. Martina Mazzucchetti for the support during the sulphate and freeze-thaw resistance tests.

Conflicts of Interest: The authors declare no conflicts of interest.

\section{References}

1. Coppola, L.; Coffetti, D.; Crotti, E.; Gazzaniga, G.; Pastore, T. An Empathetic Added Sustainability Index (EASI) for cementitious based construction materials. J. Clean. Prod. 2019, 220, 475-482. [CrossRef]

2. Kashani, A.; Provis, J.L.; Qiao, G.G.; van Deventer, J.S.J. The interrelationship between surface chemistry and rheology in alkali activated slag paste. Constr. Build. Mater. 2014, 65, 583-591. [CrossRef]

3. Palacios, M.; Banfill, P.F.; Puertas, F. Marta Palacios and Francisca Puertas, Rheology and Setting of Alkali-Activated Slag Pastes and Mortars: Effect of Organic Admixture. Mater. J. 2008, 105, 140. [CrossRef]

4. Palacios, M.; Houst, Y.F.; Bowen, P.; Puertas, F. Adsorption of superplasticizer admixtures on alkali-activated slag pastes. Cem. Concr. Res. 2009, 39, 670-677. [CrossRef]

5. Bassani, M.; Tefa, L.; Coppola, B.; Palmero, P. Alkali-activation of aggregate fines from construction and demolition waste: Valorisation in view of road pavement subbase applications. J. Clean. Prod. 2019, 234, 71-84. [CrossRef]

6. Coppola, L.; Coffetti, D.; Crotti, E.; Dell'Aversano, R.; Gazzaniga, G. The influence of heat and steam curing on the properties of one-part fly ash/slag alkali activated materials: Preliminary results. AIP Conf. Proc. 2019, 2196, 020038. [CrossRef]

7. Bondar, D.; Ma, Q.; Soutsos, M.; Basheer, M.; Provis, J.L.; Nanukuttan, S. Alkali activated slag concretes designed for a desired slump, strength and chloride diffusivity. Constr. Build. Mater. 2018, 190, 191-199. [CrossRef]

8. Long, W.-J.; Wei, J.-J.; Gu, Y.-C.; Xing, F. Research on dynamic mechanical properties of alkali activated slag concrete under temperature-loads coupling effects. Constr. Build. Mater. 2017, 154, 687-696. [CrossRef]

9. Angulo-Ramírez, D.E.; de Gutiérrez, R.M.; Puertas, F. Alkali-activated Portland blast-furnace slag cement: Mechanical properties and hydration. Constr. Build. Mater. 2017, 140, 119-128. [CrossRef] 
10. Coppola, L.; Coffetti, D.; Crotti, E. One-Part Alkali-Activated Slag Cement for Conservation of Existing Structures. ACI Spec. Publ. 2018, 330, 107-122.

11. Giosuè, C.; Mobili, A.; di Perna, C.; Tittarelli, F. Performance of lightweight cement-based and alkali-activated mortars exposed to high-temperature. Constr. Build. Mater. 2019, 220,565-576. [CrossRef]

12. Bernal, S.; Nicolas, R.S.; Provis, J.; van Deventer, J.S.J. Alkali-activated slag cements produced with a blended sodium carbonate / sodium silicate activator. Adv. Cem. Res. 2015, 28, 262-273. [CrossRef]

13. Shi, C.; Krivenko, P.V.; Roy, D.M. Alkali-Activated Cements and Concretes; Taylor \& Francis: Boca Raton, FL, USA, 2006.

14. Aydin, S.; Baradan, B. Effect of activator type and content on properties of alkali-activated slag mortars. Compos. Part B Eng. 2014, 57, 166-172. [CrossRef]

15. Bakharev, T.; Sanjayan, J.G.; Cheng, Y.B. Sulfate attack on alkali-activated slag concrete. Cem. Concr. Res. 2002, 32, 211-216. [CrossRef]

16. Komljenovic, M.; Bascarevic, Z.; Marjanovic, N.; Nikolic, V. External sulfate attack on alkali-activated slag. Constr. Build. Mater. 2013, 49, 31-39. [CrossRef]

17. Neville, A.M. Properties of Concrete; Longman: London, UK, 1995.

18. Ismail, I.; Bernal, S.A.; Provis, J.L.; Hamdan, S.; van Deventer, J.S.J. Microstructural changes in alkali activated fly ash/slag geopolymers with sulfate exposure. Mater. Struct. Constr. 2013, 46, 361-373. [CrossRef]

19. Shi, C. Strength, pore structure and permeability of alkali-activated slag mortars. Cem. Concr. Res. 1996, 26, 1789-1799. [CrossRef]

20. Fu, Y.; Cai, L.; Yonggen, W. Freeze-thaw cycle test and damage mechanics models of alkali-activated slag concrete. Constr. Build. Mater. 2011, 25, 3144-3148. [CrossRef]

21. Cai, L.; Wang, H.; Fu, Y. Freeze-thaw resistance of alkali-slag concrete based on response surface methodology. Constr. Build. Mater. 2013, 49, 70-76. [CrossRef]

22. Luukkonen, T.; Abdollahnejad, Z.; Yliniemi, J.; Kinnunen, P.; Illikainen, M. One-part alkali-activated materials: A review. Cem. Concr. Res. 2018, 103, 21-34. [CrossRef]

23. Coppola, L.; Coffetti, D.; Crotti, E.; Marini, A.; Passoni, C.; Pastore, T. Lightweight cement-free alkali-activated slag plaster for the structural retrofit and energy upgrading of poor quality masonry walls. Cem. Concr. Compos. 2019, 104, 103341. [CrossRef]

24. Coppola, L.; Coffetti, D.; Crotti, E. Pre-packed alkali activated cement-free mortars for repair of existing masonry buildings and concrete structures. Constr. Build. Mater. 2018, 173, 111-117. [CrossRef]

25. Wang, S.-D.; Scrivener, K.L. Hydration products of alkali activated slag cement. Cem. Concr. Res. 1995, 25, 561-571. [CrossRef]

26. Wang, S.-D.; Scrivener, K.L.; Pratt, P.L. Factors affecting the strength of alkali-activated slag. Cem. Concr. Res. 1994, 24, 1033-1043. [CrossRef]

27. Allahverdi, A.; Kani, E.N.; Esmaeilpoor, S. Effects of Silica Modulus and Alkali Concentration on Activation of Blast-Furnace Slag. Iran. J. Mater. Sci. Eng. 2008, 5, 32-35.

28. Bayuaji, R.; Yasin, A.K.; Susanto, T.E.; Darmawan, M.S.; Darmawan, S. A review in geopolymer binder with dry mixing method (geopolymer cement). AIP Conf. Proc. 2017, 1887, 20042. [CrossRef]

29. Coppola, L.; Coffetti, D.; Crotti, E.; Candamano, S.; Crea, F.; Gazzaniga, G.; Pastore, T. The combined use of admixtures for shrinkage reduction in one-part alkali activated slag-based mortars and pastes. Constr. Build. Mater. 2020, 248, 118682. [CrossRef]

30. Qiao, C.; Suraneni, P.; Weiss, J. Phase diagram and volume change of the $\mathrm{Ca}(\mathrm{OH})_{2}-\mathrm{CaCl}_{2}-\mathrm{H}_{2} \mathrm{O}$ system for varying $\mathrm{Ca}(\mathrm{OH})_{2} / \mathrm{CaCl}_{2}$ molar ratios. J. Mater. Civ. Eng. 2018, 30. [CrossRef]

31. Coffetti, D. Alternative Binders as Milestone of 3R Strategy for Sustainable Construction Materials. Ph.D. Thesis, University of Bergamo, Dalmine (BG), Italy, 2019. [CrossRef]

32. Ye, H.; Cartwright, C.; Rajabipour, F.; Radlińska, A. Understanding the drying shrinkage performance of alkali-activated slag mortars. Cem. Concr. Compos. 2017, 76, 13-24. [CrossRef]

33. Ye, H.; Radlińska, A. Shrinkage mechanisms of alkali-activated slag. Cem. Concr. Res. 2016, 88, 126-135. [CrossRef]

34. Shahrajabian, F.; Behfarnia, K. The effects of nano particles on freeze and thaw resistance of alkali-activated slag concrete. Constr. Build. Mater. 2018, 176, 172-178. [CrossRef]

35. Galan, I.; Perron, L.; Glasser, F.P. Impact of chloride-rich environments on cement paste mineralogy. Cem. Concr. Res. 2015, 68, 174-183. [CrossRef] 
36. Myers, R.J.; Bernal, S.A.; Provis, J.L. Phase diagrams for alkali-activated slag binders. Cem. Concr. Res. 2017, 95, 30-38. [CrossRef]

37. Myers, R.J.; Lothenbach, B.; Bernal, S.A.; Provis, J.L. Thermodynamic modelling of alkali-activated slag cements. Appl. Geochem. 2015, 61, 233-247. [CrossRef]

(C) 2020 by the authors. Licensee MDPI, Basel, Switzerland. This article is an open access article distributed under the terms and conditions of the Creative Commons Attribution (CC BY) license (http://creativecommons.org/licenses/by/4.0/). 